\title{
SIGNIFICADOS DE AUTOMEDICAÇÃO SOB A ÓTICA DE IDOSOS DE UM PROGRAMA UNIVERSIDADE ABERTA À TERCEIRA IDADE
}

\section{ARTIGO ORIGINAL}

FONSECA, Leila de Souza ${ }^{1}$

SILVA, Maria Aparecida da ${ }^{2}$

FONSECA, Leila de Souza. SILVA, Maria Aparecida da. Significados de automedicação sob a ótica de idosos de um programa universidade aberta à terceira idade. Revista Científica Multidisciplinar Núcleo do Conhecimento. Ano 04, Ed. 12, Vol. 07, pp. 93-108. Dezembro de 2019. ISSN: 2448-0959, Link de acesso: https://www.nucleodoconhecimento.com.br/saude/significados-deautomedicacao

\section{RESUMO}

Estudo descritivo, qualitativo, que objetivou conhecer os significados da prática de automedicação na visão de idosos da UNATI da PUC Goiás. Os resultados se aproximam aos de outras pesquisas na área e evidenciam que a prática da automedicação nos idosos assume maior importância, pois estes são um grupo polimedicado e estão expostos ao maior número de complicações advindas dessa prática.

Descritores: Saúde do Idoso, automedicação, Saúde Pública.

\footnotetext{
${ }^{1}$ Enfermeira. Especialista em Enfermagem em Unidade de Terapia Intensiva Adulto. Instrutora horista do curso Técnico em Enfermagem do SENAC GOIÁS.

2 Enfermeira. Mestre pela Escola de Enfermagem da Universidade Federal de Minas Gerais (UFMG). Docente do Curso de Graduação em Enfermagem da PUC GOIÁs. 


\section{INTRODUÇÃO}

A prática da automedicação é uma realidade crescente no Brasil e em outros países e tem se tornado um dos principais problemas de saúde pública e um grande desafio para as autoridades sanitárias (VITOR et al., 2008).

Nos idosos, a automedicação assume maior importância devido ao fato de que, usualmente, eles representam um grupo polimedicado. É comum nesse grupo etário a prática da automedicação com plantas medicinais e medicamentos de livre comércio, para o tratamento de problemas de saúde considerados por eles como sendo de natureza simples (CASCAES; FALCHETTI; GALATO, 2008).

Entende-se que para reverter o fenômeno da automedicação é preciso conhecer quais elementos colaboram com o crescimento dessa prática na sociedade. Apesar dos esforços, parecem poucas e ineficientes as estratégias adotadas pelo poder público para sensibilizar e conscientizar as pessoas sobre os riscos que a automedicação pode desencadear a saúde e para reduzir a sua ocorrência.

Dada à relevância do assunto, se colocam como perguntas da presente pesquisa: Quais os significados da prática de automedicação sob a ótica de idosos de um programa Universidade Aberta à Terceira Idade? Existe a prática de automedicação entre esses idosos?

Ao apresentar respostas a essas e a outras perguntas, pretende-se colaborar com a produção cientifica na área, com a construção de políticas públicas que minimizem o problema e ainda fornecer subsídios à prática dos profissionais envolvidos no cuidado à saúde dos idosos com a finalidade de melhorar a qualidade da assistência, especialmente no campo da promoção da saúde desse grupo etário.

\section{OBJETIVOS}

Conhecer os significados da prática de automedicação na visão de idosos da UNATI da PUC Goiás; destacar as características socioculturais do idoso participante da UNATI; e descrever o conhecimento do idoso sobre a prática de automedicação. 


\section{CAMINHO METODOLÓGICO}

Trata-se de um estudo descritivo, qualitativo, realizado na Pontifícia Universidade Católica de Goiás (PUC GOIÁS), na cidade de Goiânia-Goiás, com idosos do Programa Universidade Aberta à Terceira Idade (UNATI).

A coleta de dados ocorreu entre os meses de setembro e outubro de 2015, para o qual respeitou-se os seguintes critérios de inclusão: alunos com idade igual ou superior a 60 anos, frequentes e regulares às aulas das oficinas, consentido sua participação na pesquisa mediante a assinatura do Termo de Consentimento Livre e Esclarecido (TCLE). Por outro lado, foram excluídos: alunos com idade inferior a 60 anos no dia da coleta de dados; aqueles que apresentaram o desejo de retirar-se da pesquisa ou não concluíram a entrevista; aqueles que não puderam responder legalmente por si; e idosos não matriculados regularmente no semestre letivo 2015/2.

Para coleta dos dados utilizou-se a entrevista semiestruturada e uma Ficha de Informações Complementares, contendo perguntas sobre dados socioculturais dos idosos. A entrevista foi registrada em aparelho celular com capacidade para gravação de áudio e digitada em seguida, formando o corpus deste estudo.

Foram selecionados, inicialmente e aleatoriamente, 16 idosos. Porém, foi excluído desse grupo apenas um idoso, em razão de problemas técnicos com a gravação da entrevista, permanecendo 15 idosos incluídos neste estudo.

As entrevistas foram digitadas na íntegra e posteriormente lidas e relidas criticamente em de um processo análise e interpretação. Os dados foram agrupados e reagrupados dentro de um mesmo núcleo de sentido e categorizados de forma empírica, buscandose as questões centrais que emergiram durante a etapa de interpretação dos mesmos. Procedeu-se a caracterização, codificação, aproximação e reaproximação de conteúdos, temas e subtemas até culminar na síntese analítica do material obtido em campo (LEOPARDI, 2001). 
Registra-se que o presente estudo foi aprovado pelo Comitê de Ética da Pontifícia Universidade Católica de Goiás (Parecer n. 1.128.694, aprovado em 29/06/2015). Assim, todos os preceitos éticos estabelecidos na Resolução 466/2012 do Conselho Nacional de Saúde foram respeitados (BRASIL, 2012a).

\section{RESULTADOS E DISCUSSÃO}

Dos 15 idosos entrevistados, nove (60\%) são do sexo feminino e seis $(40 \%)$ masculino, evidenciando-se a participação expressiva das mulheres nas oficinas da UNATI. A faixa etária mínima encontrada é de 62 anos e a maior é de 89 anos, sendo que a média da idade identificada para este grupo é de 69,9 anos (Quadro I).

Estudos sobre automedicação entre idosos apresentam resultados semelhantes. $\mathrm{Na}$ cidade de Salgueiro-PE, de 355 indivíduos estudados, 44,9\% eram idosos com idade entre 60 a 70 anos, dos quais $69,8 \%$ deles eram do sexo feminino (BARROS SÁ; CABRAL BARROS; OLIVEIRA SÁ, 2007).

Cascaes; Falchetti; Galato (2008), ao avaliar 77 idosos participantes de grupos da terceira idade em Tubarão-SC, encontrou a média de idade 69,9 anos, sendo a maioria $(87 \%)$ do grupo pertencente ao sexo feminino. Resultados muito próximos com uma média de idade de 69,9 anos e percentual maior $(57,2 \%)$ de mulheres, também foram encontrados em outro estudo (OLIVEIRA et al., 2012).

Com relação ao estado civil, no presente estudo, cinco (33,3\%) deles declaram-se casados, outros cinco (33,3\%) viúvos, quatro $(26,6 \%)$ divorciados e apenas um $(6,7 \%)$ deles em união consensual. No que diz respeito ao núcleo domiciliar, cinco $(33,3 \%)$ idosos relatam morar sozinhos e dez $(66,7 \%)$ compartilham da presença do (a) companheiro (a), dos filhos e netos residindo em suas casas. Quanto ao grau de escolaridade, todos foram alfabetizados e dez $(66,7 \%)$ deles têm pelo menos o ensino médio completo. Dos 15 idosos, três $(20,1 \%)$ são graduados, sendo um em Pedagogia, Direito e Engenharia Elétrica. 
Ao comparar com outras pesquisas os dados se aproximam, com índices de $66 \%$ de casados e $27 \%$ de viúvos em Sorocaba-SP; de $49,5 \%$ para casados e $32 \%$ para viúvos na cidade de Goiânia-GO; e percentuais de 44\% para casados e 40\% para viúvos em Montes Claros-MG (DUARTE et al., 2012; SANTOS et al., 2013; TELLES FILHO; ALMEIDA; PINHEIRO, 2013).

Ao levantar estudos que abordam a automedicação por idosos participantes de Programas de UNATI, identificam-se, tanto convergências quanto divergências com os resultados da presente pesquisa. Estudo realizado com idosos da UNATI da Universidade do Estado do Rio de Janeiro (UERJ) aponta que $76 \%$ dos idosos eram do sexo feminino, $74 \%$ tinham o primeiro grau incompleto e a escolaridade mais elevada foi no sexo masculino, pois $23 \%$ dos homens possuíam segundo grau completo ou superior completo, enquanto, apenas $8 \%$, das mulheres estavam na mesma condição (SAYD; FIGUEIREDO; VAENA, 2001).

Mais recentemente, Alves (2014), ao estudar a polifarmácia em idosos da UNATI da Universidade Federal de Pernambuco (UFPE), identificou uma população composta em sua maioria (62,9\%) por idosos entre 60 e 70 anos, 95,6\% eram mulheres, $71,7 \%$ não tinham companheiro, a maior porcentagem $(39,6 \%)$ de idosos possuíam o 2ํㅡ grau completo, $61,6 \%$ moravam com a família e $28,3 \%$ moravam sozinhos.

Na presente pesquisa, quando questionados a respeito do ano de ingresso na UNATI da PUC Goiás, sete $(46,7 \%)$ idosos informam ter iniciado suas atividades no ano de 2015; três (20,1\%) no ano de 2013; outros três (20,1\%) em 2012, 2008 e 2007, sendo um em cada ano; os demais $(13,1 \%)$ na década de 90 , quando o programa foi criado. Vale ressaltar aqui que, desses, apenas um $(6,7 \%)$ frequenta as oficinas há uma semana e os demais 14 (93,3\%) frequentam há pelo menos um mês, destacando-se que, um desses idosos é participante da UNATI desde 1994, ano em que ingressou no Programa. Neste caso, o tempo de participação do Programa é de 17 anos.

Sobre a quantidade de oficinas frequentadas pelos participantes, nove $(60 \%)$ idosos manifestam estar matriculados em duas oficinas, cinco (33,3\%) deles em três a cinco oficinas e um (6,7\%) idoso que participa de apenas uma oficina. Observou-se que os 
idosos que participam de mais de duas oficinas são veteranos, ou seja, ingressaram no programa entre os anos de 1994 e 2015/1. Com isso pode-se dizer que, o tempo de participação na UNATI pode estar relacionado com a obtenção de novos conhecimentos e a adoção de novos hábitos de vida pelos idosos e também pelo prazer da convivência, o que mereceria aprofundar em outros estudos.

Sobre o referido aspecto, Veras; Caldas (2004) destacam a importância da participação dos idosos na UNATI, uma vez que as oficinas propostas se caracterizam como espaços de promoção da saúde física, mental e social ao explorar as várias possibilidades existentes nas universidades, possibilitando a inserção do idoso como cidadão ativo na sociedade.

No quesito acesso aos serviços de saúde, dos 15 participantes, dez (66,7\%) declaram ter plano de saúde particular. Apenas quatro (26,6\%) idosos dependem, exclusivamente, do Sistema Único de Saúde (SUS) e apenas um (6,7\%) deles utiliza os dois sistemas. Tais informações evidenciam que, todos os participantes têm acesso a algum tipo de assistência. Estes dados se correlacionam aos de outras pesquisas, como na de Alves (2014,) em que 54,7\% dos idosos da UNATI da UFPE declararam ter plano de saúde, sendo que $29,6 \%$ deles utilizavam apenas o do SUS e, 15,7\% usufruíam ambos os sistemas.

Neste sentido, vale uma reflexão: será que, a opção pelo sistema particular pode ser atribuída à má qualidade dos serviços públicos de saúde ofertados a essa população, gerando custos aos idosos frente às tarifas dos planos de saúde para pessoas nessa faixa etária são bastante elevadas? Se considerar que, a saúde é um direito de todo cidadão, garantido pela Constituição Federal de 1988, além de ser ressaltado no Estatuto do Idoso, já que esta população demanda atenção especial no que tange a assistência à saúde, entende-se que, todos os idosos devem usufruir livremente desse direito (BRASIL, 2012b; BRASIL, 2013).

De certa forma, há um consenso geral, entre os autores de que na faixa etária entre 60 e 70 anos a ocorrência da prática da automedicação é maior. As pesquisas desenvolvidas nessa área apontam que a baixa escolaridade e a não utilização de 
serviços de saúde favorecem a prática da automedicação pelos idosos. Sendo assim, grande parte dos participantes da presente pesquisa tem como pontos positivos o grau de instrução razoável, possibilidade de ampliação dos conhecimentos por meio da participação nas oficinas da UNATI e o acesso a algum tipo de assistência, embora, essa possa não corresponder às expectativas ou estar adequada às necessidades dos mesmos.

Quadro I - Características socioculturais de idosos da UNATI, PUC Goiás

\begin{tabular}{|c|c|c|c|c|c|c|c|c|c|}
\hline IE & Sexo & $\begin{array}{r}\text { Idade } \\
\text { (anos) }\end{array}$ & $\begin{array}{c}\text { Estado } \\
\text { civil }\end{array}$ & $\begin{array}{c}\text { Grau de } \\
\text { escolaridad } \\
\text { e }\end{array}$ & $\begin{array}{l}\text { Reside } \\
\text { com } \\
\text { alguém }\end{array}$ & $\begin{array}{c}\text { Ano de } \\
\text { ingress } \\
\text { o na } \\
\text { UNATI }\end{array}$ & $\begin{array}{c}\text { Tempo } \\
\text { que } \\
\text { frequen } \\
\text { ta } \\
\text { a UNATI }\end{array}$ & $\begin{array}{c}\text { Quantidad } \\
\text { e de } \\
\text { Oficinas } \\
\text { da UNATI } \\
\text { que } \\
\text { participa }\end{array}$ & $\begin{array}{l}\text { Serviço } \\
\text { de } \\
\text { saúde } \\
\text { que } \\
\text { utiliza }\end{array}$ \\
\hline $\begin{array}{l}0 \\
1\end{array}$ & $\mathrm{~F}$ & $66 a$ & Viúvo & $\begin{array}{l}\text { Ensino } \\
\text { médio comp. }\end{array}$ & Sozinho & 2015 & 6 meses & 2 & $\begin{array}{l}\text { Plano } \\
\text { de } \\
\text { saúde }\end{array}$ \\
\hline $\begin{array}{l}0 \\
2\end{array}$ & $\mathrm{~F}$ & $68 a$ & $\begin{array}{l}\text { Divorciad } \\
0\end{array}$ & $\begin{array}{l}\text { Ensino } \\
\text { médio comp. }\end{array}$ & $\begin{array}{l}\text { Com } \\
\text { filho/filha }\end{array}$ & 2015 & $\begin{array}{l}1 \\
\text { semana }\end{array}$ & 2 & $\begin{array}{l}\text { SUS e } \\
\text { plano de } \\
\text { saúde }\end{array}$ \\
\hline $\begin{array}{l}0 \\
3\end{array}$ & $\mathrm{~F}$ & $89 a$ & Viúvo & $\begin{array}{l}\text { Ensino } \\
\text { fundamental } \\
\text { inc. } / 4^{\mathrm{a}} \text { série }\end{array}$ & $\begin{array}{l}\text { Com } \\
\text { filho/filha }\end{array}$ & 1994 & 17 anos & 4 & $\begin{array}{l}\text { Plano } \\
\text { de } \\
\text { saúde }\end{array}$ \\
\hline $\begin{array}{l}0 \\
4\end{array}$ & $\mathrm{~F}$ & $75 a$ & Viúvo & $\begin{array}{l}\text { Ensino } \\
\text { fundamental } \\
\text { comp. }\end{array}$ & $\begin{array}{l}\text { Com } \\
\text { filho/filha }\end{array}$ & 2007 & 7 anos & 5 & $\begin{array}{l}\text { Plano } \\
\text { de } \\
\text { saúde }\end{array}$ \\
\hline $\begin{array}{l}0 \\
5\end{array}$ & $\mathrm{~F}$ & $65 a$ & Casado & $\begin{array}{l}\text { Ensino } \\
\text { médio inc./ } \\
3^{\circ} \text { ano }\end{array}$ & $\begin{array}{l}\text { C/compa } \\
\text { nheiro }\end{array}$ & 2015 & 6 meses & 3 & SUS \\
\hline $\begin{array}{l}0 \\
6\end{array}$ & $\mathrm{~F}$ & $70 a$ & $\begin{array}{l}\text { Divorciad } \\
\text { o }\end{array}$ & $\begin{array}{l}\text { Superior } \\
\text { comp./ } \\
\text { Pedagogia }\end{array}$ & Sozinho & 1997 & 2 anos & 2 & $\begin{array}{l}\text { Plano } \\
\text { de } \\
\text { saúde }\end{array}$ \\
\hline $\begin{array}{l}0 \\
7\end{array}$ & $\mathrm{~F}$ & $65 a$ & $\begin{array}{l}\text { Divorciad } \\
\text { a }\end{array}$ & $\begin{array}{l}\text { Ensino } \\
\text { fundamental } \\
\text { comp. }\end{array}$ & Sozinho & 2013 & $\begin{array}{l}1 \text { ano e } \\
6 \text { meses }\end{array}$ & 2 & $\begin{array}{l}\text { Plano } \\
\text { de } \\
\text { saúde }\end{array}$ \\
\hline $\begin{array}{l}0 \\
8\end{array}$ & M & $78 a$ & Casado & $\begin{array}{l}\text { Superior } \\
\text { comp./ } \\
\text { Direito }\end{array}$ & $\begin{array}{l}\text { C/compa } \\
\text { nheira }\end{array}$ & 2015 & 6 meses & 3 & $\begin{array}{l}\text { Plano } \\
\text { de } \\
\text { saúde }\end{array}$ \\
\hline $\begin{array}{l}0 \\
9\end{array}$ & M & $71 a$ & Casado & $\begin{array}{l}\text { Superior } \\
\text { comp./ Eng. } \\
\text { Elétrica }\end{array}$ & $\begin{array}{l}\text { Compan } \\
\text { heira e } \\
\text { neto }\end{array}$ & 2015 & 6 meses & 2 & $\begin{array}{l}\text { Plano } \\
\text { de } \\
\text { saúde }\end{array}$ \\
\hline $\begin{array}{l}1 \\
0\end{array}$ & $M$ & $71 a$ & Casado & $\begin{array}{l}\text { Ensino } \\
\text { médio comp. }\end{array}$ & $\begin{array}{l}\text { C/compa } \\
\text { nheira, } \\
\text { com } \\
\text { filho/filha }\end{array}$ & 2013 & 3 anos & 2 & $\begin{array}{l}\text { Plano } \\
\text { de } \\
\text { saúde }\end{array}$ \\
\hline $\begin{array}{l}1 \\
1\end{array}$ & M & $67 a$ & $\begin{array}{l}\text { União } \\
\text { consensu } \\
\text { al }\end{array}$ & $\begin{array}{l}\text { Ensino } \\
\text { médio comp. }\end{array}$ & Sozinho & 2015 & 1 mês & 2 & $\begin{array}{l}\text { Plano } \\
\text { de } \\
\text { saúde }\end{array}$ \\
\hline $\begin{array}{l}1 \\
2\end{array}$ & $M$ & $62 a$ & $\begin{array}{l}\text { Divorciad } \\
\text { o }\end{array}$ & $\begin{array}{l}\text { Superior inc./ } \\
\text { gestão } \\
\text { esportiva }\end{array}$ & Sozinho & 2015 & 1 mês & 2 & $\begin{array}{l}\text { Soment } \\
\text { e SUS }\end{array}$ \\
\hline $\begin{array}{l}1 \\
3\end{array}$ & $\mathrm{~F}$ & $70 a$ & Viúva & $\begin{array}{l}\text { Ensino } \\
\text { fundamental } \\
\text { comp. }\end{array}$ & $\begin{array}{l}\text { Com } \\
\text { filho/filha }\end{array}$ & 2013 & $\begin{array}{l}2 \text { anos e } \\
6 \text { meses }\end{array}$ & 2 & $\begin{array}{l}\text { Soment } \\
\text { e SUS }\end{array}$ \\
\hline $\begin{array}{l}1 \\
4\end{array}$ & $\mathrm{~F}$ & $65 a$ & Casada & $\begin{array}{l}\text { Ensino } \\
\text { médio comp. }\end{array}$ & $\begin{array}{l}\text { C/compa } \\
\text { nheiro }\end{array}$ & 2012 & 2 anos & 1 & $\begin{array}{l}\text { Plano } \\
\text { de } \\
\text { saúde }\end{array}$ \\
\hline $\begin{array}{l}1 \\
5\end{array}$ & M & $67 a$ & Viúvo & $\begin{array}{l}\text { Ensino } \\
\text { médio comp. }\end{array}$ & $\begin{array}{l}\text { Com } \\
\text { filho/filha }\end{array}$ & 2008 & $\begin{array}{l}\text { dois } \\
\text { meses }\end{array}$ & 4 & $\begin{array}{l}\text { Soment } \\
\text { e SUS }\end{array}$ \\
\hline
\end{tabular}

Fonte: Dados originados dos depoimentos dos idosos da UNATI da PUC Goiás, $2015 / 2$. 
Ao levantar a prática da automedicação (Quadro II) neste grupo de idosos, em algum momento da vida, identifica-se que, treze $(86,7 \%)$ idosos relatam ter usado medicamentos sem prescrição médica alguma vez na vida e os demais dois (13,3\%) afirmam não ter se automedicado nenhuma vez; sete $(46,7 \%)$ confirmam o hábito de se automedicar periodicamente e os outros oito $(53,3 \%)$ negam o uso atual de medicamentos não prescritos. Há uma contradição no depoimento de um (6,7\%) idoso entrevistado que, ora afirma nunca ter se automedicado e em outro momento reconhece ter feito uso, recentemente, de medicamento sem prescrição médica.

Observa-se que, entre os idosos que já se automedicaram alguma vez, sete $(53,8 \%)$ referem que tal hábito não faz mais parte do seu cotidiano, os demais seis $(46,2 \%)$ ainda fazem uso de medicamentos, periodicamente, sem prescrição médica. Este último dado revela que a maior parte do grupo não se automedica cotidianamente, o que pode estar relacionado ao fato de que os idosos têm adquirido conhecimento sobre os potenciais agravos à saúde gerados pelo uso indevido de medicamentos.

Neste sentido, a prática da automedicação por idosos, identificada na presente pesquisa, mostra proximidades com outros estudos, visto a convergência entre os achados de (62,5\%; 80,5\%; e 100\%), conforme apresentados pelos autores respectivamente (SOUZA; LOPES, 2007; CASCAES; FALCHETTI; GALATO, 2008; TELLES FILHO; ALMEIDA; PINHEIRO, 2013).

Contudo, outros estudiosos, Sayd; Figueiredo; Vaena (2001) encontraram diferenças menores em seus estudos sobre automedicação por idosos, nos quais $23,4 \%$ dos entrevistados disseram ter se automedicado nos últimos 30 dias. Em outras pesquisas ainda foi demonstrado valores percentuais importantes nos grupos de idosos pesquisados, quanto à adoção da automedicação, conforme demonstrado pelos autores (36,9\%; $26 \% ; 35,7 \%$ e; $15,7 \%$ ), respectivamente (MARIN et al., 2008; BORTOLON et al., 2008; SANTOS et al., 2013; ALVES, 2014).

Nesta perspectiva, ressalta-se que, o acesso aos serviços de saúde é de grande relevância na temática sobre automedicação, uma vez que, a utilização desses 
serviços e a filiação a planos de saúde restringem a prática da automedicação pelos idosos (OLIVEIRA et al., 2012).

Os idosos são o grupo etário mais propenso ao uso irracional de fármacos por serem também o mais medicalizado da sociedade (BORTOLON et al., 2008). Portanto, apesar das divergências encontradas na literatura, é fato que, esse hábito está presente nesta população e que, sua maior ou menor ocorrência desperta o interesse para a compreensão deste fenômeno.

Quadro II - Informações sobre a prática da automedicação pelos idosos: passado e presente

\begin{tabular}{|c|c|c|}
\hline IE & $\begin{array}{l}\text { Alguma vez, você já fez } \\
\text { automedicação? }\end{array}$ & Atualmente, você faz automedicação? \\
\hline I1 & Não & Não \\
\hline 12 & Sim/ Dias & Sim/ Dias \\
\hline 13 & Sim/ Dias & Sim/ Dias \\
\hline 14 & $\mathrm{Sim} /$ mais de um ano & Não \\
\hline 15 & Sim/ Meses & Não \\
\hline 16 & Sim/ Meses & Sim/ Meses \\
\hline 17 & Não & Sim/ Dias \\
\hline 18 & $\mathrm{Sim} /$ mais de um ano & Não \\
\hline 19 & Sim/ não se recorda & Sim/ Dias \\
\hline 110 & Sim/ Dias & Sim/ Dias \\
\hline 111 & Sim/ mais de um ano & Não \\
\hline 112 & $\mathrm{Sim} /$ mais de um ano & Não \\
\hline 113 & Sim/ Meses & Não \\
\hline 114 & Sim/ Meses & Sim/ Dias \\
\hline $\mid 15$ & $\mathrm{Sim} /$ mais de um ano & Não \\
\hline
\end{tabular}

Fonte: Dados originados dos depoimentos dos idosos da UNATI da PUC Goiás, $2015 / 2$. 
Ao investigar sobre a compreensão dos idosos a respeito do significado da palavra "automedicação", 14 entrevistados (93,3\%) têm o entendimento de que automedicar-se é tomar medicamentos por conta própria e sem prescrição médica. Embora as respostas não sejam exatamente iguais, percebe-se que os entrevistados I1; I2; I3; I4; I5; I6; I8; 19; I10; I11; I12; I13; I14; e I15 manifestam essa ideia central em suas falas:

Eu não me conformo que uma pessoa toma um medicamento sem saber se o organismo dela aceita aquilo... Se agente pudesse se automedicar, ninguém precisava ficar anos e anos numa faculdade estudando para ser médico (11).

Automedicação é quando a gente medica por conta da gente (I2).

Tomar remédio sem prescrição médica... É tomar remédio sem necessidade (13).

Automedicação é a gente pensar que certo remédio vai... Fazer bem e não é indicado por um profissional e a gente vai à farmácia e compra e passa a usar (14).

Automedicação é tudo aquilo que você faz sem consentimento do médico (15).

Automedicação é quando a pessoa sente algum mal estar, algum probleminha ou doencinha e vai à farmácia e compra o remédio... É isso, automedicar sem procurar o médico (16).

É medicar-se sem a autorização do profissional, no caso de um médico. É medicar sozinho, sem ter a assistência de um médico (18).

Bom, automedicação é aquela que você usa determinado remédio sem a prescrição médica. Por conta própria (19).

É o medicamento tomado em casa, com orientação de um familiar ou de uma pessoa amiga (110).

Automedicação é procurar aquisição de um remédio sem prescrição médica (111).

Automedicação, que eu entendo, é quando você toma alguma coisa sem prescrição médica (112).

É tomar (medicamento) por conta própria sem receita médica (113). 
É a gente tomar remédio sem receita médica (114).

Então, automedicação é qualquer medicamento que eu tomo, que não seja orientação médica (115).

Apenas o entrevistado 17 não informa o significado da palavra automedicação e demonstra dúvida com relação ao tema, o que pode ser notado em seu discurso, ao questionar a entrevistadora quando diz: "automedicação? ... É preço? É o preço da medicação? É um remédio mais forte, é? Eu não vou falar não porque eu não sei".

Neste caso, os resultados encontrados são iguais ao um estudo que avaliou a conduta de pessoas entre 18 e 75 anos com relação à automedicação, no qual a maior parte dos entrevistados soube conceituar o termo automedicação, ao definirem como sendo o uso/aquisição de medicamentos sem prescrição de um profissional, dos quais apenas um entrevistado não conseguiu definir de forma correta a prática (CORRÊA; GALATO; ALANO, 2012).

Ainda referentes à interpretação sobre o entendimento do termo automedicação, alguns idosos relatam que, automedicar-se é uma atitude perigosa e que pode causar prejuízos à saúde das pessoas, especialmente na terceira idade e, desaprovam essa prática entre a população, quando justificam que:

É uma coisa que me assusta muito, porque eu não me conformo que uma pessoa toma um medicamento sem saber se o organismo dela aceita aquilo (11).

Não, eu só sei o seguinte, que a gente não deve... porque às vezes a gente vai complicar, vai tomar remédio que não deve... A gente não estudou para aquilo, a gente não tem noção daquilo (12).

Eu acho que ela (automedicação) prejudica muito... Principalmente a gente que está de idade... Não pode estar tomando muito remédio assim... Eu tenho muito medo de tomar remédio sem prescrição médica (13).

Automedicação é procurar aquisição de um remédio sem prescrição médica, que pode levar a pessoa a doença grave ou a morte (111).

Você vai à farmácia e compra do farmacêutico sem receita médica. Perigoso (112). 
Eu entendo que a gente não pode tomar remédio por conta própria, porque às vezes é bom para uma coisa e prejudica outra (113).

Segundo Pereira; Vasconcelos Neto; Cruz (2014) há desvantagens na prática da automedicação, pois se somam gastos desnecessários, interações medicamentosas, retardo no diagnóstico e tratamento de doenças, reações adversas, resistência bacteriana e intoxicação. Além disso, os prejuízos e desfechos negativos relacionados à automedicação tomam proporções maiores na população idosa, devido à dificuldade de eliminação dos metabólitos que provoca o acúmulo de fármacos no organismo e aumenta o risco para reações adversas (SILVA; FONTOURA, 2014).

Somado a esses fatores, merece destaque um aspecto importante levantado pelos idosos 12 e I13, que diz respeito aos diferentes efeitos que cada medicamento pode provocar de acordo com o organismo de cada pessoa, conforme é evidenciado em suas falas quando dizem:

Às vezes a amiga fala: não... toma isso porque foi bom para mim. Nem tudo o que é bom para o outro é bom para a gente (12).

Às vezes (o medicamento) é bom para uma coisa e prejudica outra (113). Ao considerar que cada organismo pode produzir respostas diferentes, os idosos estão mais propensos a essas variações, visto que com o envelhecimento os problemas de saúde se tornam mais evidentes, o que os coloca em uma situação mais vulnerável, inclusive com o aparecimento de sensibilidades e alergias por vezes desconhecidas (SILVA; FONTOURA, 2014).

Aliado ao consumo de medicamentos, os entrevistados 15; 16; 18 e; 19 citam também o uso de alimentos e/ou plantas como remédio para o tratamento de doenças, a partir do conhecimento advindo de práticas da cultura popular. Sobre automedicar-se com outros produtos não farmacológicos, tais idosos argumentam:

Ah eu não sei te explicar direitinho, mas eu acho que (automedicação) é até chás, muita coisa que você toma (15). 
Você sabe que um chá daquilo é bom aí você vai e toma. Por exemplo: está com insônia, faz um chá de cidreira e toma, toma um suco de maracujá... (16).

Ah... medicina natural, medicina... da nossa flora... da flora tem muita coisa boa de automedicação, pode se automedicar... por exemplo, a castanha do Pará, nozes, são produtos de flora que fazem bem a saúde e que a pessoa pode tomar como complemento alimentar e ao mesmo tempo como remédio (18).

Eu acho que às vezes poderia desde que sejam esses produtos naturais, remédio natural assim como, digamos... esse feito de plantas assim... que a gente sabe que não tem efeitos colaterais nenhum... (19).

Acerca desse aspecto, Lima; Renovato (2010) afirmam que o uso de plantas medicinais como recurso terapêutico é uma prática bastante difundida no mundo, sendo observada entre a população idosa uma elevada prevalência desse hábito como prática de automedicação. Muitas vezes há a concepção de inocuidade ao ser desconsiderado a potencialidade de reações adversas e até toxicidade, relacionadas ao uso de plantas medicinais. Nesse sentido, percebe-se que a partir das falas dos entrevistados 18 e 19, essa prática está presente na população estudada e é bem aceita, pois há a ideia de que os remédios naturais não provocam nenhum dano à saúde.

Por outro lado, um dos participantes (15) acredita que os chás, quando tomados em associação com medicamentos, podem interferir nos efeitos terapêuticos dos mesmos, quando afirma que: "a pessoa ensina um chá, toma tal chá... mas... pelas coisas que eu leio, às vezes os próprios chás podem atrapalhar a medicação que você toma indicada pelo médico".

Neste sentido, algumas pesquisas comprovam que há de fato interações medicamentosas provocadas por plantas empregadas em preparações como xaropes caseiros, chás e medicamentos fitoterápicos, quando não há o controle adequado nos processos de coleta; estabilização e secagem; trituração ou pulverização; e preparo. O uso indiscriminado de plantas tem contribuído com o aumento estatístico dos eventos de intoxicação entre a população, pois muitas vezes tem-se a concepção de 
que se o medicamento natural não trouxer benefícios, também não haverá prejuízos à saúde em decorrência do seu uso (NICOLETTI et al., 2007).

Portanto, identifica-se que a compreensão dos idosos sobre o tema automedicação é ampla, pois eles acumulam consigo experiências adquiridas ao longo da vida. Como práticas de automedicação, apontam o uso de medicamentos, de alimentos e plantas (chás) para o tratamento de problemas de saúde. Assim, no grupo estudado, há aqueles que são a favor da prática de automedicação, entretanto outros acreditam ser este um hábito perigoso que causa riscos à saúde das pessoas.

\section{CONSIDERAÇÕES}

Independentemente das convergências ou não das opiniões entre os autores, nota-se que o fenômeno da automedicação é um problema de saúde pública existente na população idosa que, desperta a preocupação com os riscos que essa população corre frente às reações que podem advir com o uso inadequado/indevido de medicamentos.

Considerando-se que a prevenção ainda é "o melhor remédio", ações preventivas que minimizem a prática da automedicação, em especial pelos idosos, são necessárias. De maneira geral, os idosos entrevistados apontam pontos positivos importantes, como: o grau de instrução razoável; possibilidade de ampliação de seu conhecimento e; acesso a algum tipo de serviço de saúde, seja ele público ou particular, que, conforme evidenciado pelos autores, favorecem a diminuição da prática da automedicação neste grupo. Talvez isso se explique em razão da compreensão, das experiências e do significado sobre o assunto demonstrado pelo grupo.

Ao evidenciar que grande parte dos idosos prefere o sistema particular de saúde, propõe-se uma reflexão mais aprofundada sobre o assunto, com vistas à discussão da qualidade da assistência que os profissionais e gestores do SUS têm oferecendo a essa população. Espera-se com estes resultados, contribuir com futuras pesquisas na área, uma vez que ainda são poucos os estudos que descrevem as características 
socioculturais de idosos participantes do Programa UNATI no Brasil, correlacionandoas com a prática da automedicação nesse grupo.

Sugere-se ainda que, sejam realizadas pesquisas apontando a real contribuição das oficinas para a obtenção de novos conhecimentos e hábitos de vida pelos idosos, além da continuidade deste projeto com a participação de alunos de iniciação científica.

\section{REFERÊNCIAS}

ALVES, N. M. C. Polifarmácia em Idosos do Programa Universidade Aberta à Terceira Idade da Universidade Federal de Pernambuco. 2014. 64 f. Dissertação (Mestrado em Saúde Coletiva) - Centro de Ciências da Saúde, Universidade Federal de Pernambuco, Recife. 2014.2 Disponível em: <http://repositorio.ufpe.br/handle/123456789/12977>. Acesso em: 10/11/15.

BARROS SÁ, M.; CABRAL BARROS, J. A.; OLIVEIRA SÁ, M. P. B. Automedicação em idosos na cidade de Salgueiro-PE. Revista Brasileira Epidemiologia, v. 10, n. 1, p. 75-85, 2007. Disponível em: <http://www.scielosp.org/pdf/rbepid/v10n1/08.pdf>. Acesso em: 09/11/15.

BORTOLON, P. C. et al. Análise do perfil de automedicação em mulheres idosas brasileiras. Ciência Saúde Coletiva, v. 13, n. 4, p. 1219-1226, 2008. Disponível em: $<$ http://www.scielosp.org/pdf/csc/v13n4/18.pdf>. Acesso em: 09/11/15.

BRASIL. Ministério da Saúde. Conselho Nacional de Saúde. Resolução № 466, de 12 de dezembro de 2012. Aprova as seguintes diretrizes e normas regulamentadoras de pesquisas envolvendoseres humanos. Brasília, 2012a. Disponível em: <http://conselho.saude.gov.br/resolucoes/2012/Reso466.pdf>. Acesso em: 31/03/15.

- Constituição da República Federativa do Brasil: texto constitucional promulgado em 5 de outubro de 1988, com as alterações adotadas pelas Emendas Constitucionais nos 1/1992 a 68/2011, pelo Decreto Legislativo ํo 186/2008 e pelas Emendas Constitucionais de Revisão nos 1 a 6/1994. 35. ed. Brasília: Câmara dos Deputados, Edições Câmara, 2012b. 454 p. 
. Legislação sobre o idoso: Lei no 10.741, de 1ํ de outubro de 2003 (Estatuto do idoso) e legislação correlata [recurso eletrônico]. 3. ed. Brasília: Câmara dos Deputados, Coordenação Edições Câmara, 2013. 124 p.

CASCAES, E. A.; FALCHETTI, M. L.; GALATO, D. Perfil da automedicação em idosos participantes de grupos da terceira idade de uma cidade do sul do Brasil. Arquivos Catarinenses de Medicina, v. 37, n. 1, p. 63-39, 2008. Disponível em: $<$ http://www.acm.org.br/revista/pdf/artigos/537.pdf>. Acesso em: 12/03/15.

CORRÊA, T. S.; GALATO, D.; ALANO, G. M. Condutas relacionadas à automedicação de adultos: um estudo qualitativo baseado na técnica de grupo focal. Revista Brasileira de Farmácia, v. 93, n. 3, p. 315-320, 2012 . Disponível em: <http://rbfarma.org.br/files/rbf-2012-93-3-8.pdf>. Acesso em: 15/03/15.

DUARTE, L. R. et al. Hábitos de consumo de medicamentos entre idosos usuários do SUS e de plano de saúde. Cadernos Saúde Coletiva, v. 20, n. 1, p. 64-71, 2012. Disponível em: $<$ http://iesc.ufrj.br/cadernos/images/csc/2012_1/artigos/CSC_v20n1_64-71.pdf>. Acesso em: 09/11/15.

LEOPARDI, M. T. Corpo do relatório de pesquisa nas diversas abordagens. In: LEOPARDI, M. T.; BECK, C. L. C.; NIETSCHE, R. M. B. G. Metodologia da pesquisa na saúde. Santa Maria: Pallotti, 2001. p. 293-310.

LIMA, S. C. S.; RENOVATO, R. D. As representações e usos de plantas medicinais em homens idosos no cotidiano. Disponível em: <http://periodicos.uems.br/index.php/index/index>. Acesso em: 15/11/15.

MARIN, M. J. S. et al. Caracterização do uso de medicamentos entre idosos de uma unidade do Programa Saúde da Família. Use of medicines by the elderly in a Family Health Program unit in Brazil. Cadernos de Saúde Pública, v. 24, n. 7, p. 1545-1555, 2008. Disponível em: < http://www.scielosp.org/pdf/csp/v24n7/09.pdf>. Acesso em: 09/11/15. 
NICOLETTI, M. A. et al. Principais interações no uso de medicamentos fitoterápicos. Infarma, v. 19, n. 1/2, p. 32-40, 2007. Disponível em: <http://www.saudedireta.com.br/docsupload/1339893751infa09.pdf>. Acesso em: 15/11/15.

OLIVEIRA, M. A. et al. Automedicação em idosos residentes em Campinas, São Paulo, Brasil: prevalência e fatores associados. Cadernos de Saúde Pública, v. 28, n. 2, p. 335-345, 2012. Disponível em: <http://www.scielosp.org/pdf/csp/v28n2/12.pdf>. Acesso em: 09/11/15.

OLIVEIRA, R. S. et al. Gerência de um centro de atenção integral à saúde do idoso. Revista de Enfermagem do Centro-Oeste Mineiro, v. 1, n. 1, p. 131-135, 2011. Disponível em: <file://C:/Users/win7/Documents/TCC\%20III/artigos/Oliveira\%20201 1.pdf $>$. Acesso em: 12/11/15.

PEREIRA, D. T. M.; VASCONCELOS NETO, E. L.; CRUZ, N. P. S. Profile of selfmedication among older adults cared for in basic health units. Journal of Nursing UFPE On line, v. $8, \quad$ n. $11, \quad$ p. 3868-3873, 2014. Disponível em:<http://www.revista.ufpe.br/revistaenfermagem/index.php/revista/article/viewArticl e/5180>. Acesso em: 15/11/15.

SANTOS, T. R. A. et al. Consumo de medicamentos por idosos, Goiânia, Brasil. Revista de Saúde Pública, v. 47, n. 1, p. 94-103, 2013. Disponível em: <http://www.scielo.br/pdf/rsp/v47n1/13.pdf>. Acesso em: 09/11/15.

SAYD, J.; FIGUEIREDO, M. C.; VAENA, M. L. H. T. Automedicação na população idosa do núcleo de atenção ao idoso da UNATI/UERJ. In: VERAS, R. et al. Velhice numa perspectiva de futuro saudável. Rio de Janeiro: UERJ, UnATI, 2001. p. 115-134. Disponível em: <http://www.crde-unati.uerj.br/publicacoes/textos_Unati/unati2 .pdf\#page $=114>$. Acesso em: 10/11/15.

SILVA, Y. A.; FONTOURA, R. Principais Consequências da Automedicação em Idosos. Revista de Divulgação Científica Sena Aires, v. 3, n. 1, p. 69-75, 2014. 
Disponível em: <http://revistafacesa.senaaires.com.br/index.php/revisa/article/vie w/118>. Acesso em: 15/11/15.

SOUZA, A. C.; LOPES, M. J. M. Práticas terapêuticas entre idosos de Porto Alegre: uma abordagem qualitativa. Revista da Escola de Enfermagem da USP, v. 41, n. 1, p. 52-56, 2007. Disponível em: <http://www.scielo.br/pdf/reeusp/v41n1/v41n1a06>. Acesso em: 09/11/15.

TELLES FILHO, P. C. P.; ALMEIDA, A. G. P.; PINHEIRO, M. L. P. Automedicação em idosos: um problema de saúde pública. Revista Enfermagem UERJ, v. 21, n. 2, p. 197201, 2013. Disponível em: <http://www.facenf.uerj.br/v21n2/v21n2a10.pdf>. Acesso em: 09/11/15.

VERAS, R. P.; CALDAS, C. P. Promovendo a saúde e a cidadania do idoso: o movimento das universidades da terceira idade. Ciência \& Saúde Coletiva, v. 9, n. 2, p. 423-32, 2004. Disponível em: <http://www.scielosp.org/pdf/csc/v9n2/20396.pdf>. Acesso em: 12/11/15.

VITOR, R. S. et al. Padrão de consumo de medicamentos sem prescrição médica na cidade de Porto Alegre, RS. Ciência \& Saúde Coletiva, 13, Sup, p. 737-743, 2008. Disponível em: <http://www.scielosp.org/pdf/csc/v13s0/a24v13s0>. Acesso em: 12/03/15.

Enviado: Novembro, 2019.

Aprovado: Dezembro, 2019. 